\title{
Climatic potential for viticulture in Central Chile
}

\author{
C. MONTES'*, J.F. PEREZ-QUEZADA', A. PEÑA-NEIRA' and J. TONIETTO² \\ ' Universidad de Chile, Facultad de Ciencias Agronómicas, Casilla 1004, Santiago, Chile \\ ${ }^{2}$ Empresa Brasileira de Pesquisa Agropecuária, Centro Nacional de Pesquisa de Uva e Vinho, Caixa Postal \\ | 30-95700-000, Bento Gonçalves, Brazil \\ * Present address: Centro de Estudios Avanzados en Zonas Aridas (CEAZA), Casilla 599, La Serena, Chile. \\ Corresponding author: Mr Carlo Montes, fax +56 5I 204378, email carlo.montes@ceaza.cl
}

\begin{abstract}
Background and Aims: Central Chile represents a large area of viticultural potential for high-quality wine production. Although climate has been commonly accepted as one of the main drivers of Chilean viticultural success, its main features have not been described from a viticultural perspective. Our work focused on analysing the spatial climatic structure in this area with respect to the potential for grapevine production.

Methods and Results: Climatic indices were used to estimate heat accumulation during the growing season, thermal regime during ripening and the potential water balance at the end of the growth cycle. These indices were calculated for 54 weather stations and clustered using hierarchical classification. The spatial variability in climatic potential was well explained by differences in heat accumulation and by March thermal amplitude.

Conclusions: General patterns showed that the ripening of grapes was associated with low night-time temperatures. Proximity to the sea had a strong influence, and there was a dominant north-south orientation of the climatic groups. Significance of the Study: This study described the differences and relative importance of major climatic factors in Central Chile, providing an increase in knowledge about the climate of Chilean wine-producing regions.
\end{abstract}

\section{Abbreviations \\ CI Cool Night Index; DI Dryness Index; HI Heliothermal Index; MCC multicriteria climatic classification; MTA March thermal amplitude}

Keywords: climate variability, climatic classification, climatic index, viticultural zoning

\begin{abstract}
Introduction
Environmental variables are considered the most influential factors on grapevine production and berry composition. The existing components of the physical environment (e.g. climate, soil properties, topography and geology) can lead to characteristic expression in different grapevine cultivars, resulting in temporal and spatial variations in wine quality and typicity (Winkler et al. 1974, Gladstones 1992). The interaction among these environmental factors is often defined as the viticultural terroir (Falcetti 1994, Vaudour 2003). The influence of climate on wine quality is well known, through the effect of both regional and local-scale climatic conditions during the growing season, and by its interannual variability, which generates variations in grapevine growth and then in berry composition (Coombe 1987, Gladstones 1992, Jones and Davis 2000, Jones et al. 2005, Soar et al. 2008). Among climate variables, air temperature is recognised as having the greatest effect on physiological behaviour of the grapevine and on chemical changes in the berry occurring during its formation and maturity (Jackson 2000, Carbonneau et al. 2007), affecting plant vigour, ripening rate and harvest date (Jackson and Lombard 1993). Temperature is also known to determine the concentration of aromatic and colour compounds in certain cultivars under specific nighttime temperatures (Kliewer and Torres 1972, Kliewer 1973, Fregoni and Pezzutto 2000).

Central Chile is the main wine-producing area of the country (Figure 1). In this zone, the Andes Mountains to the
\end{abstract}

east and the Coastal range to the west characterise the regional topography, with the viticultural areas located mainly at the bottom of the valleys. The climate is controlled by the climatological persistence of the subtropical high-pressure system of the southeastern Pacific, which shows a strengthening and southward displacement in summer, thus regulating synoptic scale variability in Central Chile (Garreaud and Aceituno 2007). During wintertime and after the high-pressure system weakening, the increasing eastward passage of midlatitude cold-frontal systems through the region influences provides the maximum yearly rainfall amounts in those months, with a declining frequency of precipitation events northward that generates a north-south rainfall gradient and a very distinct precipitation annual cycle (Falvey and Garreaud 2007). These general largescale features determine the dominant Mediterranean type of climate under which Chilean viticulture is carried out.

Worldwide, a large number of studies examining the climatic features have provided the description of different terroirs and the identification of winemaking regions using different methodologies (e.g. Tonietto 1999, Asselin et al. 2001, Bonnardot et al. 2002, Tonietto and Carbonneau 2004). Despite the importance of Chile as a wine-producing country, and the relevance of climate in providing a wide range of grapevine growing possibilities, there have been few studies that have documented the climatic characteristics and suitability. In this context, the aim of this study was to provide increase knowledge of climate conditions for viticulture in Central Chile, 

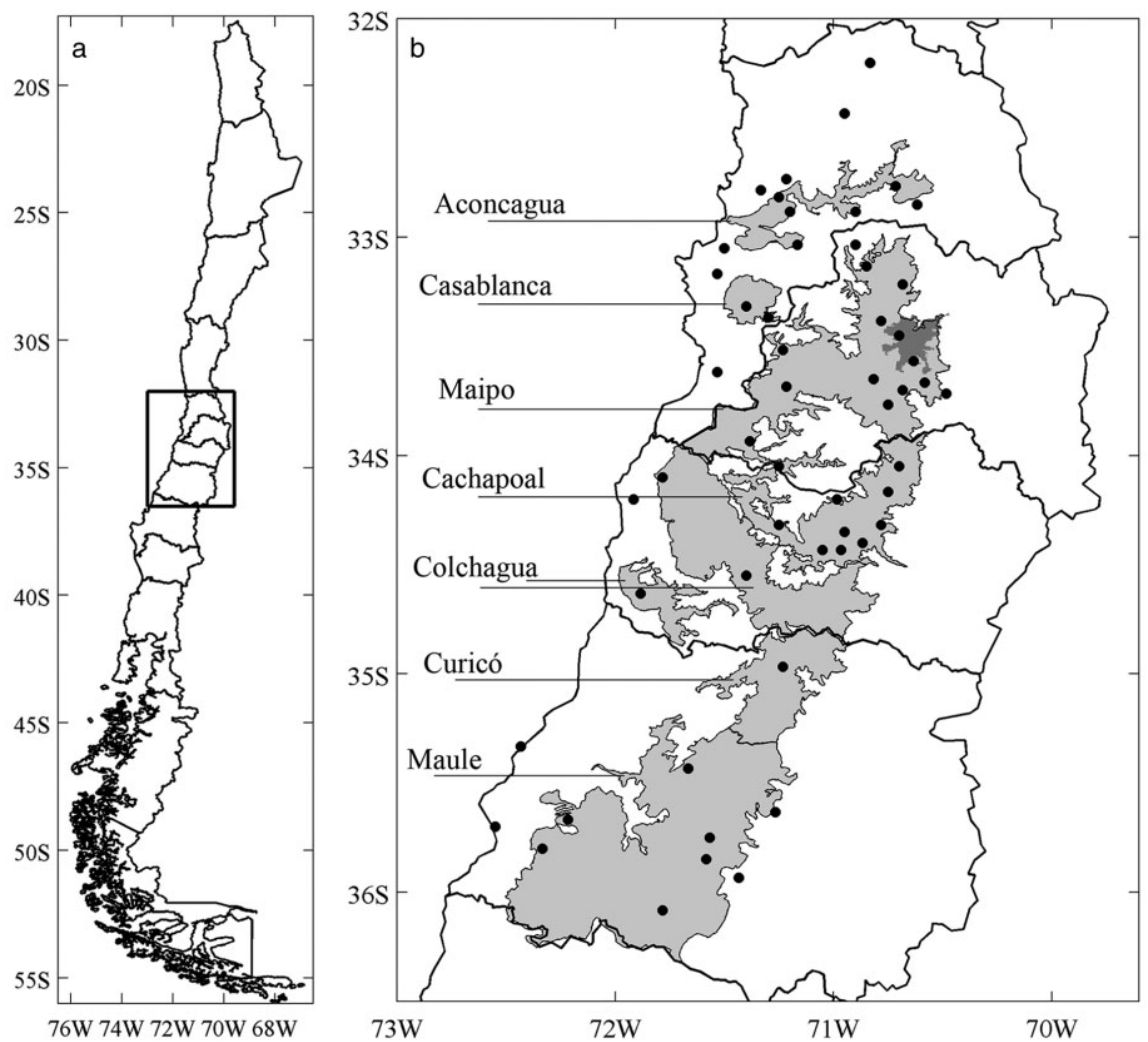

Figure 1. (a) Location of the study area in Central Chile (black lines are administrative divisions); (b) spatial distribution of the weather stations (black circles) and the included viticultural valleys (grey polygons). The darker polygon in the Maipo valley shows the city of Santiago.

describing the variability in climatic potential for grapevine production using climatic indices and classifying this variability into distinguishable groups.

\section{Materials and methods}

Study area and climatic data

Seven (from a total of 14) Chilean viticultural valleys (Aconcagua, Casablanca, Maipo, Cachapoal, Colchagua, Curicó and Maule) were included in this study, which were delimited according to the Appellation of Origin System of Chilean Wines (Figure 1). These seven valleys represent a cultivated area of about 95000 ha, equivalent to $85 \%$ of the Chilean viticultural area (Wines of Chile 2011), and the main cultivars grown are Cabernet Sauvignon (32.9\% of surface), Merlot (12.2\%), Chardonnay (11.7\%), Sauvignon Blanc $(9.7 \%)$, Carménère $(5.2 \%)$, Pinot Noir $(2.6 \%)$, Syrah $(1.2 \%)$, among others such as Cabernet Franc, Riesling, Carignan and Gewurztraminer (SAG, 2010). This region is characterised by a typical Mediterranean type of climate with maximum temperatures ranging between 25 and $35^{\circ} \mathrm{C}$ during the growing season (September-March), and a total annual precipitation varying from 300 to $900 \mathrm{~mm}$, concentrated in the cold season (June-August). Vineyards are typically grown under irrigated conditions and trained mainly in vertical shoot-positioning system.

Monthly mean data of temperature (mean, maximum and minimum), rainfall and pan evaporation (Class A) over the period 1990-2005 for a set of 54 weather stations were used. These weather stations were located within the abovementioned viticultural valleys (Figure lb), from $32^{\circ} 13$ to $36^{\circ} 05^{\prime} \mathrm{S}$, and from $70^{\circ} 29$ to $72^{\circ} 33^{\prime} \mathrm{W}$, representing a transect of 440 and $220 \mathrm{~km}$ approximately in latitude and longitude, respectively. This climatic database provided information not only about the currently cultivated zones but also about zones close to the viticultural valleys that could have viticultural potential.

\section{Climatic indices and classification}

The classification methodology was based on the multicriteria climatic classification (MCC) system proposed by Tonietto and Carbonneau (2004), which consists of the joint use of three climatic indices: the heliothermal index (HI), cool night index (CI) and dryness index (DI). Several studies have used this climatic classification approach worldwide (e.g. Hormazábal et al. 2002, Blanco-Ward et al. 2007, Ferrer et al. 2007, Jones et al. 2009), but no study has been performed for Chilean viticultural regions, which would also contribute to the validation of the classification system at the global scale.

Developed by Huglin (1978), the HI relates the air temperature during the active period of vegetative growth (OctoberMarch in the Southern Hemisphere) and a coefficient of day length that varies according to the latitude. The HI provides information about the local heat summation considering the average and maximum temperatures, weighting the accumulated temperatures to the daytime period (Tonietto and Carbonneau 2004):

$$
\mathrm{HI}=\sum_{01-\mathrm{oct}}^{31-\mathrm{mar}} \frac{\left[\left(T_{m}-10\right)+\left(T_{x}-10\right)\right]}{2} d,
$$

where $T_{m}$ is the average air temperature $\left({ }^{\circ} \mathrm{C}\right), T_{x}$ is the mean maximum air temperature $\left({ }^{\circ} \mathrm{C}\right)$, and $d$ is the day length coefficient applied between 40 and $50^{\circ}$ latitude (Huglin 1978, Tonietto and Carbonneau 2004). In the present study, this latitude correction factor was applied for all the weather stations located at latitudes $\geq 33.3^{\circ} \mathrm{S}$, as was performed previously by Hall and Jones (2010) for Australian viticultural regions and by Jones et al. (2010) for the western USA. According to these authors, a time-integrated day-length factor for a given latitude and day of the year, calculated taking into account some astronomical parameters using the equations from Glarner (2006), can be obtained as a linear function of the accumulated day lengths 
from 1 October to 31 March, using the upper and lower values of $d$ originally proposed by Huglin and Schneider (1998) for European regions (see Hall and Jones 2010 for calculation details). The calculated day lengths for the growing season (a potential daily sunshine length) in the Southern Hemisphere between 30 and $50^{\circ} \mathrm{S}$ of latitude, and the corresponding correction factor $(d)$ are shown in Figure S1 (Online Supporting Information). It is clear that the latitude and time affect the day length, and that at latitudes $\geq 33.3^{\circ} \mathrm{S}$, the $d$ values are higher than 1.0 (latitudes at which this factor was applied, as done by Hall and Jones 2010). Huglin and Schneider (1998) proposed a lower limit for grapevine cultivation fixed at $\mathrm{HI}=1400$ to reach an adequate ripening process for different grapevine cultivars (required to reach a certain sugar concentration).

The CI takes into account the minimum temperatures of March in the Southern Hemisphere, a period in which the ripening process usually occurs or finishes. This climatic factor is known as one of the important features for the synthesis of the compounds responsible for colour and aroma in grapes (Kliewer and Torres 1972, Kliewer 1973). Combining CI with other climatic indices can give a better assessment of the qualitative potential for grapevine-growing regions (Tonietto and Carbonneau 2004). The calculation corresponds to the average minimum air temperature of March $\left({ }^{\circ} \mathrm{C}\right)$ (Tonietto 1999).

The DI describes the hydric component of climate, indicating the presence or the absence of drought condition and its intensity. The DI takes into account the vineyard evaporative demand, the bare soil evaporation and the precipitation, indicating the soil potential water availability, and the level of regional dryness (Tonietto and Carbonneau 2004). DI is calculated over the same 6-month period as HI according to the following formula:

$$
\mathrm{DI}=W_{0}+P+T_{V}+E_{S}
$$

where DI ( $\mathrm{mm})$ is the estimated soil water content at the end of the growing season, $W_{0}$ is the initial soil water content, $P$ is the precipitation $(\mathrm{mm}), T_{V}$ is the potential vineyard transpiration $(\mathrm{mm})$ and $E_{S}$ is the direct soil evaporation $(\mathrm{mm}) . T_{V}$ and $E_{S}$ are calculated as follows:

$$
\begin{gathered}
T_{V}=E T P * k, \\
E_{S}=\frac{E T P}{N}(1-k) \mathrm{JPm},
\end{gathered}
$$

where ETP is the potential evapotranspiration, and $k$ is a coefficient of radiation absorption by the vineyard. For ETP calculation, the MCC system is defined using the Penman (1948) method, but because we did not have all the necessary data for its estimation, for the present study, we used the pan evaporation. In equation $4, N$ is the number of days of the month, and $J P m$ is the number of days with effective soil evaporation (calculated dividing $P$ by $5 \mathrm{~mm}$ ), which should be equal to or lower than $N$. For the Southern Hemisphere, the $k$ values used are 0.1 in October, 0.3 in November and 0.5 from December to March.

To perform a qualitative description of climate in a viticultural sense, and after performing a global classification of the climatic indices, Tonietto and Carbonneau (2004) proposed different climate classes for viticulture. Classification according to the ranges of the three indices distinguishes climates ranging from very cool $(\mathrm{HI} \leq 1500)$ to very warm $(\mathrm{HI}>3000)$; climates from very cool nights $\left(\mathrm{CI} \leq 12^{\circ} \mathrm{C}\right)$ to warm nights $\left(\mathrm{CI}>18^{\circ} \mathrm{C}\right)$; and climates ranging from very dry (DI $\leq-100 \mathrm{~mm}$ ) to humid (DI $>150 \mathrm{~mm}$ ).
In addition to the above-described climatic indices, we used the mean thermal amplitude (MTA) of March as a complementary index (i.e. the difference between maximum and minimum temperatures of March). March was chosen using the same criteria as for the CI. This thermal parameter has been considered an important factor influencing grape composition (e.g. Mullins et al. 1992, Ramos et al. 2008). For each time series of $n$ elements, this index was calculated as:

$$
\mathrm{MTA}=\frac{1}{n} \sum_{1}^{n}\left(T_{x m}-T_{n m}\right),
$$

where $T_{x m}$ and $T_{n m}$ are the mean maximum and minimum temperature in March $\left({ }^{\circ} \mathrm{C}\right)$, respectively.

\section{Statistical procedure}

Multivariate statistical analyses have been used as an integrated approach to estimate the individual effects of climatic variables on climatic variability in agricultural conditions (e.g. BlancoWard et al. 2007, Evrendilek and Berberoglu 2008). To obtain a multicriteria climatic grouping, a hierarchical classification (cluster analysis) with the four selected climatic indices was used. The standardised Euclidean distance was used as the measure of similarity, which according to Wilks (2006), is defined for points $x_{i}$ and $x_{j}$ in the $K$-dimensional space of the respective vectors as:

$$
D_{i, j}=\left[\sum_{k=1}^{K} \frac{\left(x_{i, k}-x_{j, k}\right)^{2}}{\sigma_{k}^{2}}\right]^{1 / 2},
$$

where $\sigma_{k}^{2}$ is the variance of the $x_{k}$ samples. This data standardisation avoids the effect of scales and units of variables on the group discrimination. After calculating the Euclidean distance, Ward's (1963) hierarchical minimum variance method was used as the clustering algorithm. According to Wilks (2006), Ward's method merges the pairs of clusters that will result in the minimum sum of squared distances between the points and the centroids of their respective group, summed over the resulting groups. Between all the possible two-group combinations, the pair selected to be merged is the one that minimises the sum of squared distance between the points and the centroids of their respective group, summed over the resulting groups. The total within-group error sum of squares in one step $\left(S_{i}\right)$, with $K$ groups, $J$ variables and $M$ elements in each group, is defined as:

$$
S_{t}(K)=\sum_{k=1}^{K} \sum_{j=1}^{J} \sum_{m=1}^{M}\left(x_{m j k}-\bar{x}_{j k}(m)\right)^{2},
$$

where $x_{m j k}$ is the value of the $j^{\text {th }}$ variable, from $m^{\text {th }}$ observations in $k^{\text {th }}$ groups, and $\bar{x}_{j k}(m)$ is the mean value of the group (Wilks 2006). Once the different groups were defined, a multiple discriminant analysis (MDA) was performed to find the sources of discrimination between the resulting groups and to describe the existing differences between groups based on the values of the four climatic indices (Dillon and Goldstein 1984).

\section{Results and discussion}

\section{General climatic features}

The distribution of HI, CI, DI and MTA for Central Chile weather stations is presented in Figure 2. The average values found for each index were $\mathrm{HI}=2075$ (temperate), $\mathrm{CI}=9.4^{\circ} \mathrm{C}$ (very cool nights), DI $=-174 \mathrm{~mm}$ (very dry) and $\mathrm{MTA}=16.2^{\circ} \mathrm{C}$. For $\mathrm{HI}$, the 

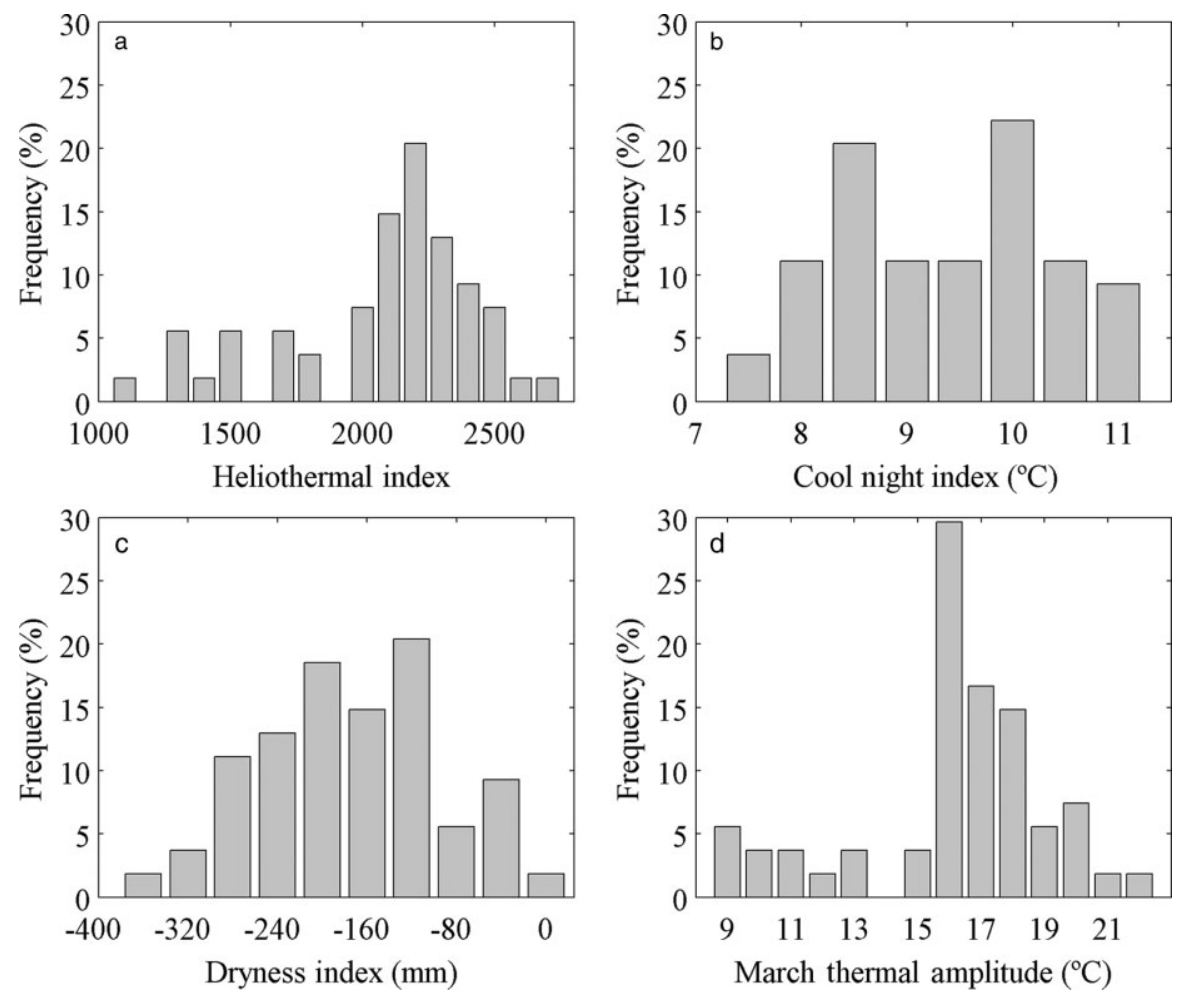

Figure 2. Frequency histograms for $\mathrm{HI}, \mathrm{Cl}, \mathrm{DI}$ and MTA. values range from 1089 to 2664; for $\mathrm{CI}$, the values range from 7.3 to $11.2^{\circ} \mathrm{C}$; for DI, the values range from -372 to $-13 \mathrm{~mm}$; and for MTA, the values range from 8.7 to $21.6^{\circ} \mathrm{C}$.

For HI, the observed distribution reveals a wide range of viticultural classes according to the MCC system, including 5 of the 6 climatic groups originally defined worldwide (from very cool to warm); some weather stations showed values below 1400 for HI, therefore, an heliothermal potential unsuitable for grapevine cultivation (Figure 2a) according to Huglin and Schneider (1998). Most of the weather stations (59\%) were classified as having temperate warm and warm climates according to their HI value, which is thermally suitable for the ripening of the main cultivated varieties, such as Cabernet Sauvignon or Merlot. However, some physiological problems could occur in zones with high heat accumulation, which could affect the aromatic potential of grapes in the earliest cultivars, such as Sauvignon Blanc and Chardonnay. Similar ranges of climate classes for HI were described for other viticultural regions, such as the Miño River Valley in Spain (Blanco-Ward et al. 2007) and Australia (Hall and Jones 2010). Because the period and procedure of calculation (i.e. monthly or daily data) can be different for other works, these comparative values should be considered only as a reference of values found in the literature.

For CI, a relatively narrow range of minimum temperatures and a bimodal distribution was found, with a maximum frequency at 8.5 and $10^{\circ} \mathrm{C}$ (Figure $2 \mathrm{~b}$ ). A lower variability was observed for CI compared with that described for other viticultural regions, which in general, have higher values and ranges of night-time temperatures, such as Bordeaux in France $\left(12.9^{\circ} \mathrm{C}\right.$, cool nights class), Sacramento and Fresno in the USA (13.2 and $14.9^{\circ} \mathrm{C}$, cool nights and temperate nights classes, respectively), Napier in New Zealand $\left(12.6^{\circ} \mathrm{C}\right.$, cool nights class), or Cape Town in South Africa $\left(14.2^{\circ} \mathrm{C}\right.$, temperate nights class) (Tonietto 1999, Tonietto and Carbonneau 2004, Jones et al. 2009). Moreover, all the weather stations recorded a minimum temperature for March below $12^{\circ} \mathrm{C}$, i.e. showed very cool nights conditions for ripening of grapes (Figure $2 \mathrm{~b}$ ). This relatively cold nocturnal condition has been described for some winegrowing regions of Germany (Baden and Mosel), France (Bourgogne and Champagne), Spain (Miño Valley) and Australia (Mount Gambier and Nuriootpa) (Tonietto and Carbonneau 2004, Blanco-Ward et al. 2007, Jones et al. 2009). However, this feature can be regarded as a climate characteristic of Central Chile, as no similar spatially uniform low-temperature condition has been reported for other grape-producing regions, according to the MCC system.

Consistent with the dominant Mediterranean type of climate in Central Chile, characterised by the prevailing dry conditions in the warm season, only negative values were found for DI (moderately dry and very dry). Nevertheless, the DI amplitude reveals variations in climatic water demand and potential hydric balance at the end of the growing season (Figure 2c). From a viticultural perspective, this negative hydric balance can be favourable because it implies almost no rainfall events during the grape-growing and fruit-ripening period. This could, for example, reduce the development of some diseases or reduce the vigour of the vines (e.g. Willocquet and Clerjeau 1998). This climatic feature has been described for other winegrowing regions with a Mediterranean-type climate, including Spain (La Mancha, Rioja and Tarragona), Portugal (Porto, Évora and Lisbon), France (Montpellier, Perpignan and Toulon), the USA (Fresno, Portland and Sacramento) and Australia (Mildura, Mount Gambier and Nuriootpa) (Tonietto and Carbonneau 2004, Jones et al. 2009). Given the almost total absence of rainfall during the growing season, this dryness condition determines that irrigation is required in vineyards of Central Chile. Therefore, comparisons of DI with other winegrape growing regions must be considered as a reference of a mean climatic water demand.

A wide temperature range was found for the MTA (from 8.7 to $21.6^{\circ} \mathrm{C}$ ), with the highest frequency of values of around $16^{\circ} \mathrm{C}$ (Figure $2 \mathrm{~d}$ ). This relatively large thermal amplitude may involve favourable aspects for grape properties and quality of wines produced under such thermal conditions, as found by Ramos et al. (2008) in the Priorat region of Spain (with an average 
August-September thermal amplitude of $10.1^{\circ} \mathrm{C}$ ), where a higher diurnal temperature range during ripening period resulted in higher quality of red wines.

The linear relationship between climatic indices and geographical variables is shown in Table 1. A low but significant positive correlation between HI and elevation was found. A higher correlation between $\mathrm{HI}$ and distance to the ocean reveals a decrease of heliothermal potential closer to the sea. The increase of $\mathrm{HI}$ in higher elevations is the opposite of what would be expected and could be explained by the fact that the stations located at lower elevations are also those closer to the ocean, consequently a combined effect of both geographical factors is revealed at this regional scale. An effect associated with the degree of continentality is reflected in a reduction in heat summation (HI) and thermal amplitude (MTA) closer to the ocean, which generates no variation in minimum temperatures (CI). This mesoscale phenomena should be addressed in future works considering factors such as topography-conditioned surface

Table 1. Correlation matrix between climatic indices and geographical variables.

\begin{tabular}{lrrrc}
\hline & HI & CI & DI & MTA \\
\hline HI & 1.00 & - & - & - \\
CI & -0.09 & 1.00 & - & - \\
DI & $\mathbf{0 . 4 1}$ & 0.06 & 1.00 & - \\
MTA & $\mathbf{0 . 9 1}$ & $-\mathbf{0 . 4 3}$ & $-\mathbf{0 . 3 9}$ & 1.00 \\
Distance to the ocean & $\mathbf{0 . 6 6}$ & -0.08 & -0.11 & $\mathbf{0 . 6 4}$ \\
Latitude & 0.13 & 0.24 & -0.18 & 0.12 \\
Elevation & $\mathbf{0 . 2 8}$ & $\mathbf{- 0 . 2 8}$ & -0.15 & $\mathbf{0 . 3 4}$ \\
\hline
\end{tabular}

Coefficients in bold are significant at level $P<0.05$. circulation and land/sea breezes (e.g. Bonnardot et al. 2005, Bonnardot and Cautenet 2009). Also, a significant negative correlation between HI and DI was found, showing that the warmer zones have the most negative potential water balance.

Figure 3 shows a scatter plot relating the four climatic indices (see also Table 1). A wide range of values was found for most combinations of climatic indices. Although low, yet statistically significant, the negative correlation coefficient between DI and HI (Figure 3b) shows a trend of higher heliothermal potential for zones with a higher water deficit by the end of the season, contrasting coastal with inland zones. In the same way, and with a relatively high dispersion, the relationship between CI and MTA (Figure 3d) indicates a reduction in thermal amplitude (MTA) in those zones with higher night-time temperatures (CI). In contrast to the previous case, a clear linear relationship was found between HI and MTA (Figure 3c), where the zones with higher heliothermal potential are more likely to experience wider thermal amplitudes in March. Therefore, those zones with higher suitability related to the heliothermal potential could benefit from wider thermal amplitudes during the ripening period, allowing higher potential of sugar concentration in berries with an adequate synthesis of aromatic and colour compounds for well-adapted varieties (Kliewer 1973). Nevertheless, in zones with high HI values, the concentration of organic acids might be affected (mainly malic and tartaric acid, which would be reduced by cell respiration), as well as some aromatic compounds (Coombe 1987).

\section{Climatic groups in Central Chile}

The results of the hierarchical classification done using the four climatic indices are shown in Figure 4 and displayed as a dendrogram (Figure 4a) and the distance between clusters as a function of the analysis stage (Figure $4 \mathrm{~b}$ ). When similar clusters are compared at the first stages, the distance between them is low, and it increases at the next stages of the analysis (Wilks
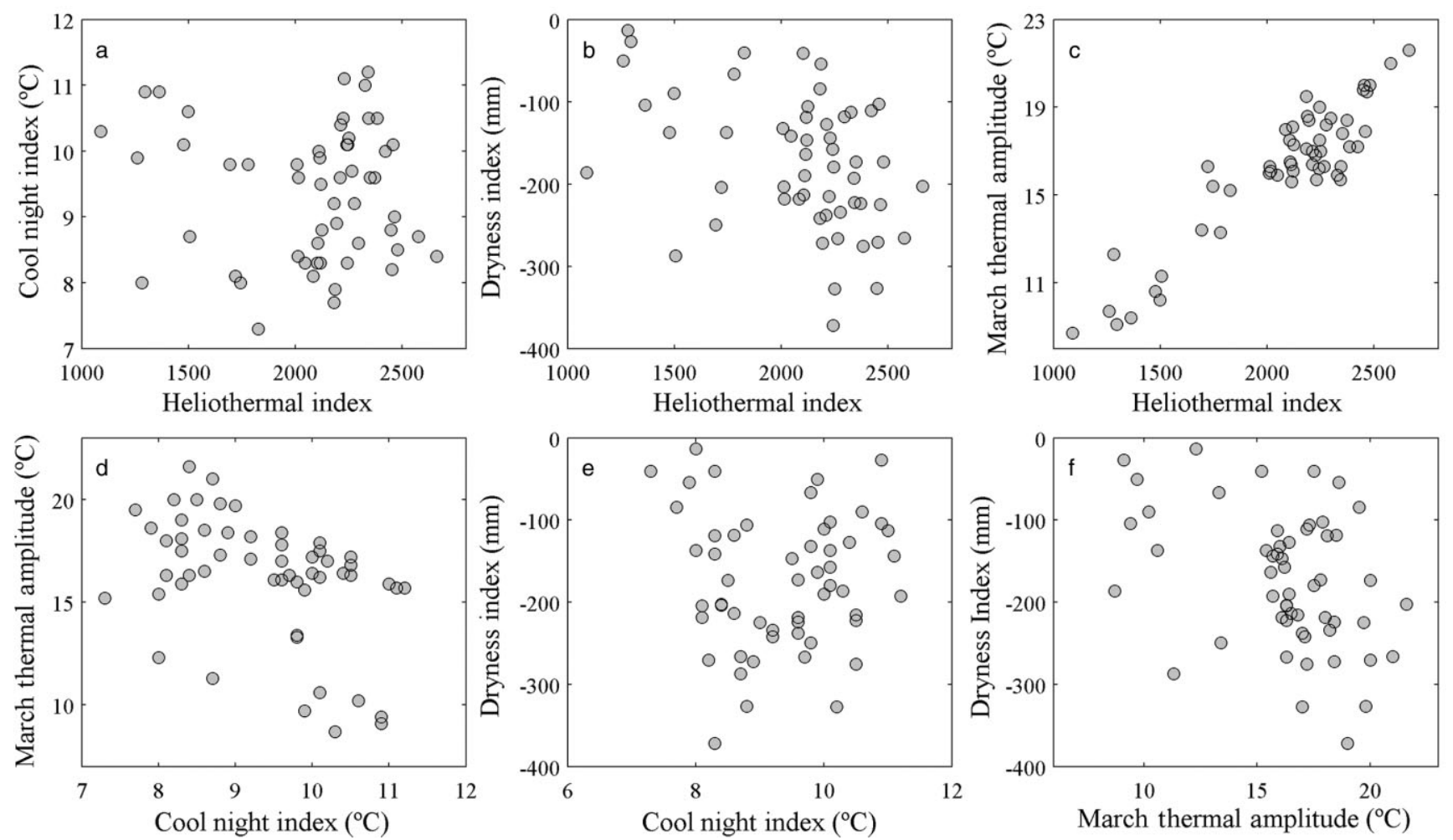

Figure 3. Scatter plots for the relationships position between $\mathrm{HI}, \mathrm{Cl}$, DI and MTA. 


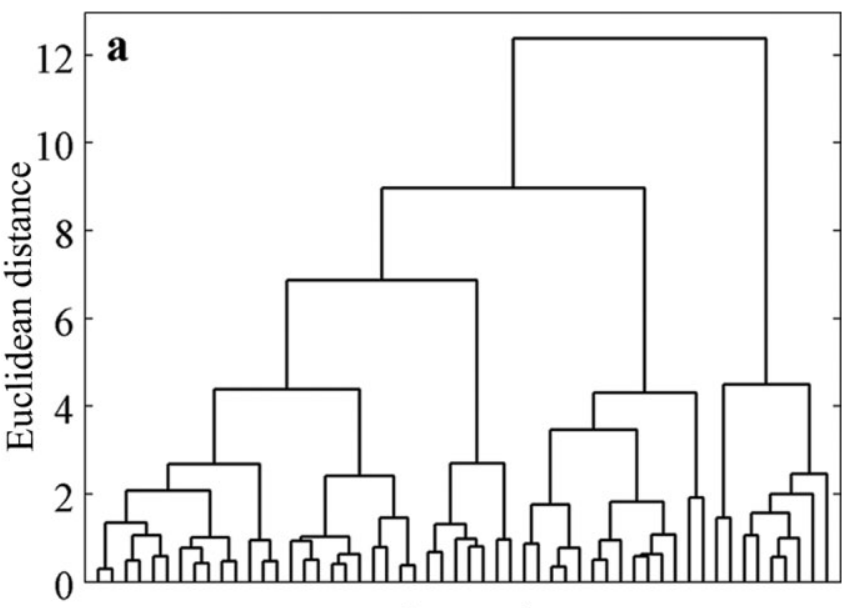

Weather stations

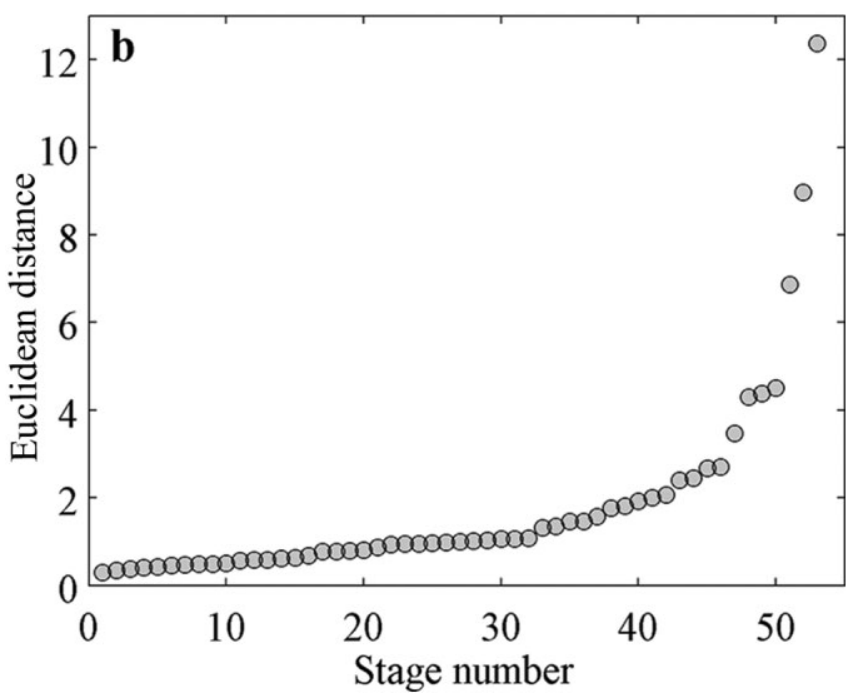

Figure 4. (a) Dendrogram of the hierarchical classification of the 54 weather stations and (b) the distance between clusters as a function of the stage of analysis.

2006). It can be observed that around stage 47, there is a significant increase in distance between clusters, determining an adequate number of five clusters or climatic groups to be considered. Although a number of 5-7 clusters could be retained, we chose the lowest option to facilitate the interpretation and discussion of each group.

The statistical results of the MDA are presented in Table 2. The Wilks' lambda indicates the discrimination capacity of the MDA ( 0 for perfect discrimination capacity and 1 for null), showing for the final model a high proportion of the total variance $(98 \%$, lambda $=2 \%)$ is explained by differences among the groups in the discriminant functions (DF), with a highly significant difference between the centroid of each group $(P<0.001)$ after a chi-square test. As can be seen through the small increase of the Wilks' lambda resulting when each index is removed (Wilks' lambda for each index), the four climatic indices have a similar statistical contribution to the discriminant capacity. However, the close statistical relationship between HI and MTA described previously can result in a smaller increase in the discrimination capacity, given the similar contribution by both indices.

Three DF were considered as a means to characterise the five groups. Correlations between variables (climatic indices) and DF are shown in Table 2 along with the cumulative proportion of
Table 2. Correlation between climatic indices and DFs, and significance statistics of the MDA (Wilks' lambda).

\begin{tabular}{lrrrr}
\hline Variable & DF1 & DF2 & DF3 & $\begin{array}{r}\text { Wilks' } \\
\text { lambda } \\
\mathbf{( \% )}\end{array}$ \\
\hline HI & -0.539 & -0.711 & -0.294 & 2.8 \\
DI & 0.689 & -0.673 & -0.149 & 4.3 \\
CI & 0.157 & 0.323 & -0.925 & 4.1 \\
MTA & -0.847 & -0.496 & -0.189 & 3.2 \\
Eigenvalue & 5.331 & 3.092 & 0.412 & - \\
Cumulative & 0.603 & 0.953 & 0.999 & - \\
$\quad$ proportion & & & & \\
\hline
\end{tabular}

Final model: Wilks' lambda $=2 \% ; F=27.2 ; P<0.001$.

the total variance explained by each DF, with values of $60.3 \%$ for DF1, 35\% for DF2 and $4.6 \%$ for DF3. The high discriminating capacity of DFl is related to its negative correlation with MTA and HI, and its positive correlation with DI and CI, with a higher contribution from MTA. For DF2, the heliothermal potential appears to be the most contributing characteristic, followed by a similar correlation with DI. In DF3, the CI has the higher contribution.

The position of climatic groups with respect to the DF is displayed in Figure 5. As was said, the DFl explains the highest proportion of the variance, and a comparison of DF1 and DF2 shows a clear discrimination for the groups 3, 4 and 5, with an overlap for groups 1 and 2. Given the negative correlation with MTA and HI for DFl, group 5 appears as the one with the lower thermal amplitudes and heat accumulation, and conversely for groups on the negative side of the axis. Due to its positive correlation with DFl, along the DI axis, the groups are separated in an inverse way to MTA and HI. Comparing DF2 and DF3 shows how they discriminate groups 1,2 and 3 from groups 4 and 5, in which HI and DI have the highest correlation showing a combined discrimination for the zones with more negative water balance and higher heliothermal potential. Given the similar correlations between climatic indices and the first two DF, a similar group separation for each index can be seen, except for the night-time thermal condition represented by CI, which displays a low discrimination capacity.

Five groups with significant climatic characteristics and differences in their climatic potential for grapevine cultivation were identified. The descriptive statistics of the climatic indices for each group are shown in Table 3, including the statistical significance of differences between means after a Tukey's test. Also, the distance to the sea and elevation of each climatic group are shown in Table 4. The spatial distribution of the weather stations of each climatic group is shown in Figure 6, and its characteristics are discussed below.

Group 1 is the most frequent, formed by 16 weather stations located mainly in the central part of the valleys from Aconcagua to the north and Maule to the south. This climatic group has a high heliothermal potential (mean $\mathrm{HI}=2259$, climate class warm), offering suitable climatic conditions cultivation of the main varieties (e.g. Cabernet Sauvignon, Merlot, Carménère and Syrah). It has the highest nocturnal temperature during the ripening period $\left(\mathrm{CI}=10.3^{\circ} \mathrm{C}\right)$, a relatively high MTA $\left(16.5^{\circ} \mathrm{C}\right)$ and the driest condition (DI $=-165 \mathrm{~mm}$ ) with groups 4 and 5 . A similar combination of values of the MCC system indices was described previously in the Australian viticultural region of 
$\bigcirc \mathrm{G} 1 \quad$ * G2 $\square \mathrm{G} 3 \quad \bigcirc \mathrm{G} 4 \quad \square \mathrm{G} 5$

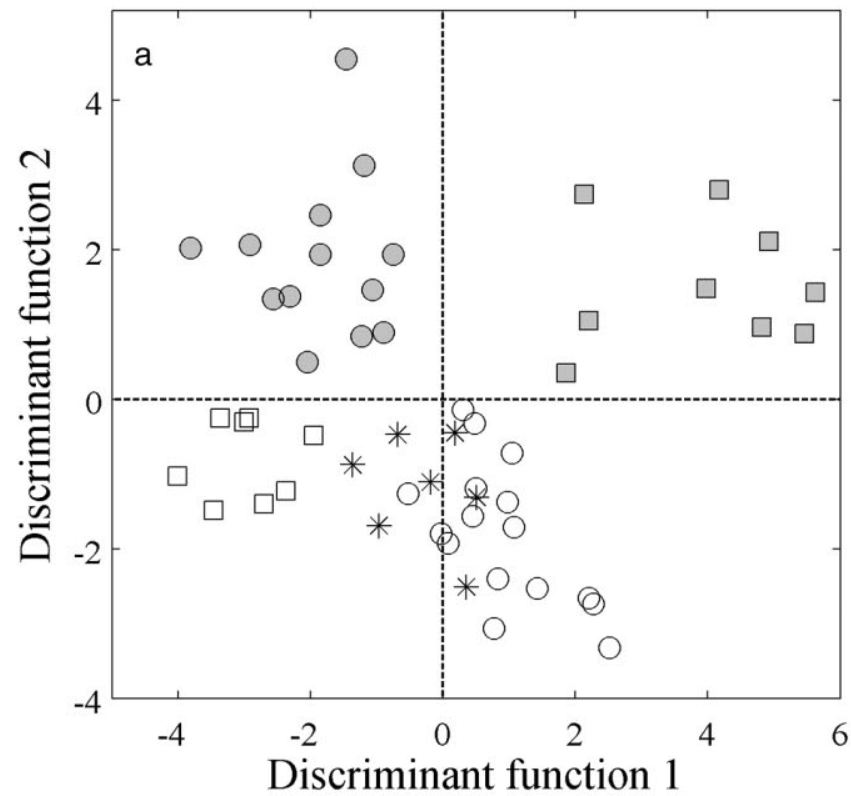

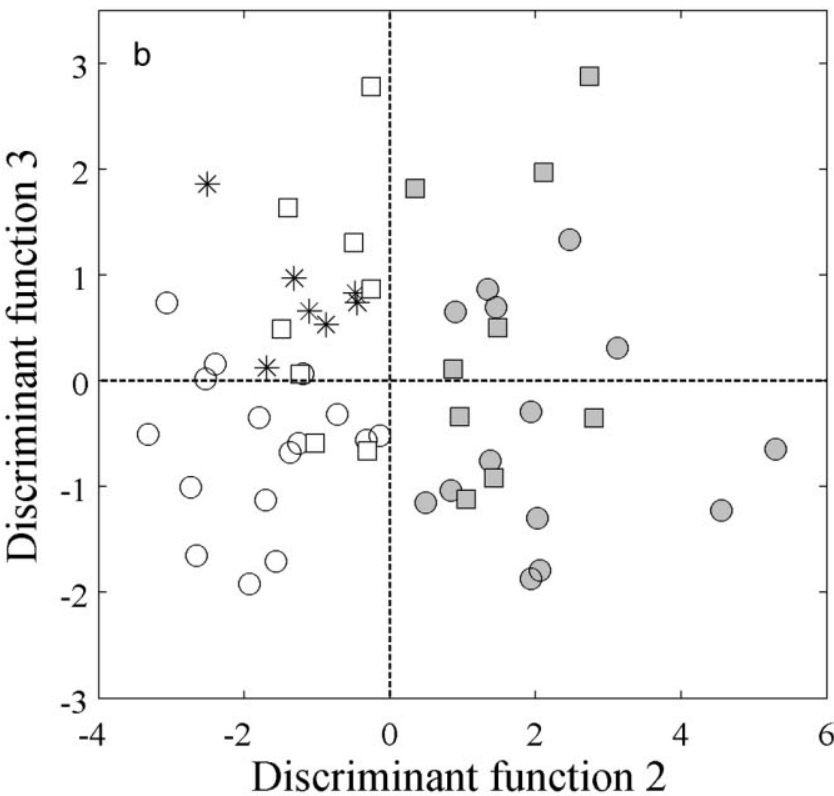

Figure 5. Position of the climatic groups in the first three discriminant functions. The combination of DF1/DF3 is not shown because it added little information. G1, group 1; G2, group 2; G3, group 3; G4, group 4; and G5, group 5.

Table 3. Descriptive statistics of climatic indices of the five climatic groups.

\begin{tabular}{|c|c|c|c|c|c|c|c|c|c|c|}
\hline & \multicolumn{5}{|c|}{ Heliothermal Index } & \multicolumn{5}{|c|}{ Cool Night Index $\left({ }^{\circ} \mathrm{C}\right)$} \\
\hline & Mean & Median & SD & Min. & Max. & Mean & Median & SD & Min. & Max. \\
\hline Group 1 & $2259 \ddagger$ & 2240 & 126 & 2089 & 2459 & $10.3+$ & 10.1 & 0.5 & 9.5 & 11.2 \\
\hline Group 2 & $2225 \ddagger$ & 2251 & 220 & 2016 & 2373 & $9.6 \neq$ & 9.6 & 0.3 & 9.2 & 10.2 \\
\hline Group 3 & $2441 \dagger$ & 2460 & 156 & 2194 & 2664 & $8.6 \S$ & 8.6 & 0.3 & 8.2 & 9.0 \\
\hline Group 4 & $1988 \S$ & 2095 & 264 & 1281 & 2297 & $8.2 \pi$ & 8.2 & 0.4 & 7.3 & 8.8 \\
\hline \multirow[t]{3}{*}{ Group 5} & $1440 \mathbb{1}$ & 1477 & 215 & 1089 & 1781 & $10.1 †$ & 10.1 & 0.7 & 8.7 & 10.9 \\
\hline & \multicolumn{5}{|c|}{ Dryness Index (mm) } & \multicolumn{5}{|c|}{ March Thermal Amplitude $\left({ }^{\circ} \mathrm{C}\right)$} \\
\hline & Mean & Median & SD & Min. & Max. & Mean & Median & SD & Min. & Max. \\
\hline Group 1 & $-165+$ & -161 & 47 & -275 & -102 & $16.5 \ddagger$ & 16.4 & 0.8 & 15.6 & 17.9 \\
\hline Group 2 & $-250 \ddagger$ & -238 & 37 & -327 & -218 & $17.2 \ddagger$ & 17.0 & 0.9 & 16.1 & 18.4 \\
\hline Group 3 & $-264 \ddagger$ & -268 & 65 & -372 & -173 & $19.9+$ & 19.9 & 1.0 & 18.4 & 21.6 \\
\hline Group 4 & $-121 \dagger$ & -188 & 70 & -219 & -13 & $16.8 \ddagger$ & 16.9 & 1.8 & 12.3 & 19.5 \\
\hline Group 5 & $-133+$ & -104 & 90 & -287 & -27 & $10.6 \S$ & 10.2 & 1.7 & 8.7 & 13.4 \\
\hline
\end{tabular}

Different symbols in the same column indicate significant differences according to Tukey's test $(P<0.05)$. Max., maximum; Min., minimum; SD, standard deviation.

Nuriootpa and Medford in the USA (Tonietto and Carbonneau 2004). Other viticultural regions have been reported to have similar values, such as Valle de Uco in Argentina $(\mathrm{HI}=2287$, $\mathrm{CI}=11.2^{\circ} \mathrm{C}, \mathrm{DI}=-75 \mathrm{~mm}$; the latter being significantly different from group 1) and Cape Town in South Africa (HI =2174, a higher $\mathrm{CI}=14.2^{\circ} \mathrm{C}$, DI $=-270 \mathrm{~mm}$ ) (Tonietto 1999).

Group 2 consists of seven weather stations, located in the Aconcagua, Maipo, Cachapoal and Maule Valleys. The values of HI and MTA are statistically equal to group 1. Differences with group 1 lie in DI and CI values. This group has a slightly colder night-time temperatures $\left(\mathrm{CI}=9.6^{\circ} \mathrm{C}\right)$ and a drier condition ( $\mathrm{DI}=-250$, very dry class), and given the irrigation practices, these features could give this group the possibility
Table 4. Distance to the sea and elevation of the five climatic groups.

\begin{tabular}{lrrrrrrrr}
\hline & \multicolumn{3}{c}{ Distance to the sea $(\mathbf{k m})$} & & \multicolumn{3}{c}{ Elevation (masl) } \\
\cline { 2 - 3 } & Min. & Mean & Max. & & Min. & Mean & Max. \\
\hline Group 1 & 27.8 & 103.5 & 134.9 & & 97 & 320 & 870 \\
Group 2 & 24.4 & 62.0 & 133.2 & & 140 & 281 & 500 \\
Group 3 & 72.2 & 86.6 & 107.7 & & 123 & 508 & 762 \\
Group 4 & 1.1 & 101.5 & 149.8 & & 60 & 377 & 1310 \\
Group 5 & 0.5 & 15.3 & 38.6 & 7 & 158 & 360 \\
\hline
\end{tabular}




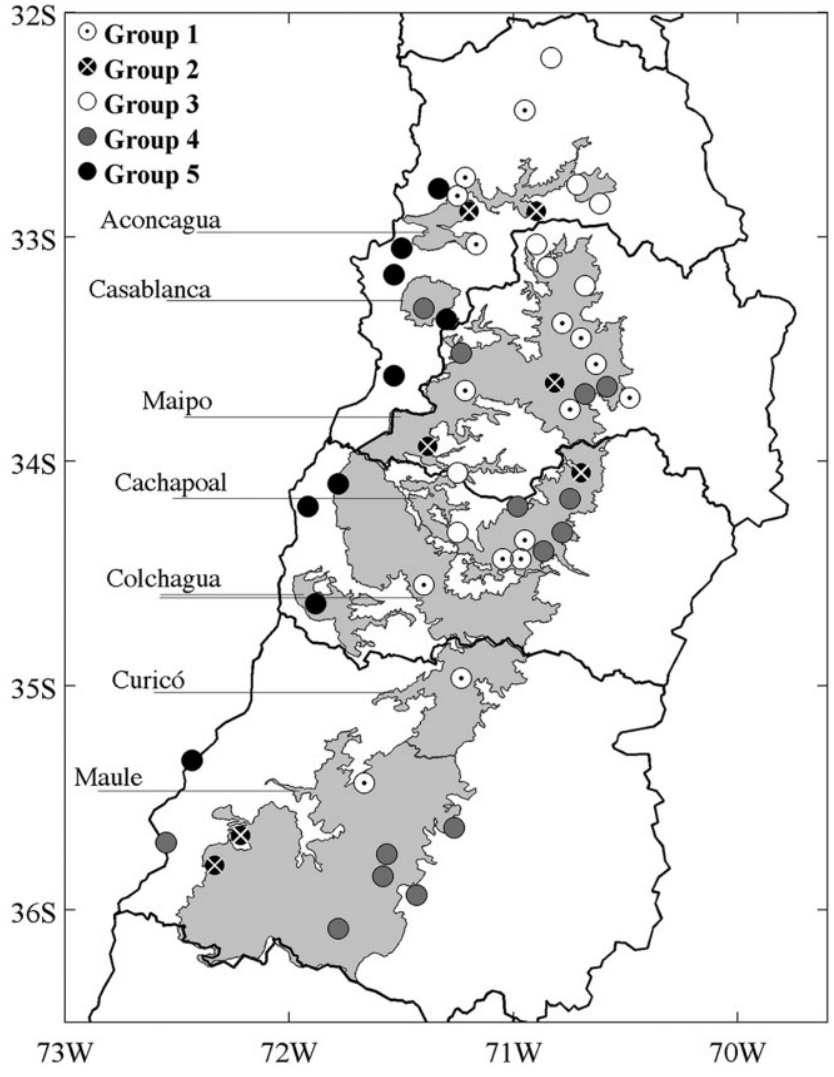

Figure 6. Spatial distribution of the weather stations for the five climatic groups.

to obtain similar berry and wine qualities than group 1 for red grapevine varieties.

Group 3 is composed of eight weather stations located mainly in the northern portion of the study area in the Aconcagua, Maipo and Cachapoal Valleys, and also in surrounding zones. This is the group with the highest heat accumulation $(\mathrm{HI}=2441$, climate class warm $)$, a value that indicates a suitable condition for later ripening varieties such as Carménère or Syrah. For cool-climate varieties of importance in Central Chile, such as Pinot Noir, Chardonnay or Sauvignon Blanc, this thermal condition might be unfavourable given the probability of reduction in grape quality by loss of organic acids and aromatic compounds (e.g. Jackson and Lombard 1993). The low night-time temperatures $\left(\mathrm{CI}=8.6^{\circ} \mathrm{C}\right)$ and high MTA $\left(19.9^{\circ} \mathrm{C}\right)$ for this climate group are important climatic features that can potentially generate an increase in quality-associated compounds for appropriate varieties such as Syrah. Similar climatic features as group 3 have been described to occur in terms of $\mathrm{HI}$ in regions such as Montpellier in France $(\mathrm{HI}=2336$, $\left.\mathrm{CI}=15.2^{\circ} \mathrm{C}, \mathrm{DI}=-50 \mathrm{~mm}\right)$ and Ciudad Real in Spain $(\mathrm{HI}=$ 2522, $\mathrm{CI}=13.3^{\circ} \mathrm{C}$, DI $=-86 \mathrm{~mm}$ ) (Tonietto 1999), with differences for CI and DI according the MCC system.

Group 4 is the second largest group, formed by 14 weather stations located near the coast, such as the Casablanca Valley, and mainly near the eastern edge of the Maipo, Cachapoal and Maule Valleys, which are the highest zones near the Andes. Their position likely explains this group's lower mean heliothermal potential $(\mathrm{HI}=1988$, temperate class), which may limit the potential cultivation of red wine varieties with higher thermal requirements, such as Cabernet Sauvignon or Carménère. These locations could be suitable for early-ripening varieties, such as Pinot Noir or Riesling. This group has the lowest nocturnal temperatures during the ripening period $\left(\mathrm{CI}=8.2^{\circ} \mathrm{C}\right)$ and relatively high MTA $\left(16.8^{\circ} \mathrm{C}\right)$, which may also promote the expression of the well-adapted varieties (e.g. Pinot Noir or Sauvignon Blanc). Similar climatic features have been found in Valladolid in Spain $\left(\mathrm{HI}=2020, \mathrm{CI}=10.9^{\circ} \mathrm{C}, \mathrm{DI}=-20 \mathrm{~mm}\right)$, Barolo in Italy $\left(\mathrm{HI}=1960, \mathrm{CI}=14.6^{\circ} \mathrm{C}, \mathrm{DI}=90 \mathrm{~m}\right)$ and Bordeaux in France $\left(\mathrm{HI}=1995, \mathrm{CI}=12.9^{\circ} \mathrm{C}, \mathrm{DI}=147 \mathrm{~mm}\right)$, showing these European regions higher values for DI and CI (Tonietto 1999, Jones et al. 2009).

Nine weather stations located near the coastal zones of Central Chile compose group 5. This group had the lowest thermal accumulation $(\mathrm{HI}=1440$, class very cool) and therefore the lower potential for grape maturity. Due to the proximity to the sea, the weather stations of this group experience the moderating influence of the Pacific Ocean, thus some stations record low temperatures resulting in a HI value lower than the theoretical limit of 1400 proposed by Huglin and Schneider (1998) for grapevine cultivation. As expected, this group has also the lowest MTA $\left(10.6^{\circ} \mathrm{C}\right)$, as a direct influence of proximity to the sea. Along with group 1, this group shows the highest mean value for CI $\left(10.1^{\circ} \mathrm{C}\right)$. However, CI remains under $12^{\circ} \mathrm{C}$, which demonstrates the low discrimination capacity of $\mathrm{CI}$ for viticultural regions in Central Chile. Except for drier condition, similar cool condition for viticulture were found in regions such as Argentina (Río Negro; $\mathrm{HI}=1435, \mathrm{CI}=5.5^{\circ} \mathrm{C}, \mathrm{DI}=31 \mathrm{~mm}$ ), Germany (Würzburg; $\mathrm{HI}=1472, \mathrm{CI}=9.7^{\circ} \mathrm{C}, \mathrm{DI}=200 \mathrm{~mm}$ ), or France (Champagne; $\mathrm{HI}=1492, \mathrm{CI}=9.9^{\circ} \mathrm{C}, \mathrm{DI}=106 \mathrm{~mm}$ ) (Tonietto 1999, Jones et al. 2009).

\section{Conclusions}

A statistically based climate classification and description was performed, extending over a large portion of Chilean viticultural area. Using four climatic indices (HI, CI, DI and MTA), important differences in climatic potential and suitability for grapevine cultivation were identified. A wide range of potential to reach maturity was observed using the HI, from cold zones with a very low thermal suitability to others theoretically not restrictive for any variety. The MTA showed a close spatial relationship and discriminatory capacity with HI. Despite the wide range of DI values, results showed a generalised dryness potential condition at the end of the growing season. This condition corresponds to a distinctive climatic feature of Central Chile as compared with other wine-producing regions of the world. However, these last results should be considered as a climatic feature and not as an indicator of vineyard hydric status because irrigation in Central Chile is a widespread practice, making difficult a comparison between viticultural zones using this index. As for night-time temperature conditions, and according to the MCC system, the values found for CI indicate general very cool conditions in relation to other viticultural regions of the world. Results show also that CI was not an appropriate climate descriptor, given its lack of discrimination capacity. However, MTA appears as a very useful tool to characterise the thermal regime during grape-ripening period in Central Chile.

Cluster analysis facilitated the description of five climatic groups with different viticultural characteristics. The trend to north-south orientation of these groups reveals the importance of geographic factors on the spatial structure at a macroclimatic scale, such as the proximity to the sea, the elevation and the degree of continentality. This spatial arrangement is in accordance to the recently approved system of viticulture appellations of origin (SAG 2010), partially replacing the former system that was based only on areas that followed the orientation of the 
watersheds (east-west). We think that the classification presented here will help to a better understanding of the climatic characteristics and potential for growing grapes within the area of Central Chile and also could represent a good basis for future works at finer spatial and temporal scales.

\section{Acknowledgements}

This work was supported by the CYTED project 'Zoning Methodologies and Applications in the Viticultural Regions of IberoAmerica'. The authors gratefully acknowledge the Dirección Meteorológica de Chile for providing the climate data, and the contributions of Dr Richard E. Plant for the constructive comments and suggestions to the original manuscript.

\section{References}

Asselin, C., Barbeau, G. and Morlat, R. (2001) Approche de la composante climatique à diverses échelles dans le zonage viticole. Le Bulletin de l'Organisation Internationale de la Vigne et du Vin 74, 843-844.

Blanco-Ward, D., Garcia-Queijeiro, J.M. and Jones, G.V. (2007) Spatial climate variability and viticulture in the Mino River Valley of Spain. Vitis 46, 63-70.

Bonnardot, V. and Cautenet, S. (2009) Mesoscale atmospheric modeling using a high horizontal grid resolution over a complex coastal terrain and a wine region of South Africa. Journal of Applied Meteorology and Climatology 48, 330-348.

Bonnardot, V., Planchon, O., Carey, V.A. and Cautenet, S. (2002) Diurnal wind, relative humidity and temperature variation in the StellenboschGroot Drakenstein wine producing area. South African Journal of Enology and Viticulture 23, 62-71.

Bonnardot, V., Planchon, O. and Cautenet, S. (2005) Sea breeze development under an offshore synoptic wind in the South-Western Cape and implications for the Stellenbosch wine-producing area. Theoretical and Applied Climatology 81, 203-218.

Carbonneau, A., Deloire, A. and Jaillard, B. (2007) La vigne: physiologie, terroir, culture (Dunod: Paris).

Coombe, B.G. (1987) Influence of temperature on composition and quality of grapes. Proceedings of the Symposium on Grapevine Canopy and Vigour Management. Acta Horticulturae 206, 23-35.

Dillon, W.R. and Goldstein, M. (1984) Multivariate analysis: methods and applications (Wiley: New York).

Evrendilek, F. and Berberoglu, S. (2008) Quantifying spatial patterns of bioclimatic zones and controls in Turkey. Theoretical and Applied Climatology $91,35-50$.

Falcetti, M. (1994) Le terroir. Qu'est-ce qu'un terroir? pourquoi l'étudier? pourquoi l'enseigner? Le Bulletin de l'Organisation Internationale de la Vigne et du Vin 67, 246-275.

Falvey, M. and Garreaud, R. (2007) Wintertime precipitation episodes in Central Chile: associated meteorological conditions and orographic influences. Journal of Hydrometeorology 8, 171-193.

Ferrer, M., Pedocchi, R., Michelazzo, M., Gonzalez-Neves, G. and Carbonneau, A. (2007) Delimitación y descripción de regiones vitícolas del Uruguay en base al método de clasificación climática multicriterio utilizando índices bioclimáticos adaptados a las condiciones del cultivo. Agrociencia 11, 47-56.

Fregoni, C. and Pezzutto, S. (2000) Principes et premières approches de l'indice bioclimatique de qualité de Fregoni. Le Progrès Agricole et Viticole 117, 390-396.

Garreaud, R. and Aceituno, P. (2007) Atmospheric circulation and climatic variability. In: The physical geography of South America. Eds. T. Veblen, K. Young and A. Orme (Oxford University Press: New York) pp. 45-59. Gladstones, J.S. (1992) Viticulture and environment (Winetitles: Adelaide).

Glarner, H. (2006) Length of day and twilight. http://www.gandraxa.com/ length_of_day.xml [accessed 14/03/11].

Hall, A. and Jones, G. (2010) Spatial analysis of climate in winegrapegrowing regions in Australia. Australian Journal of Grape and Wine Research 16, 389-404.

Hormazábal, S., Lyon, G. and Carbonneau, A. (2002) Variabilité et limite du macroclimat viticole méditerranéen des Départements de l'Aude, de l'Hérault et du Gard, dans le Midi de la France. Progrès Agricole et Viticole 119, 102-110.

Huglin, P. (1978) Nouveau mode d'évaluation des possibilités héliothermiques d'un milieu viticole. Comptes Rendus de l'Académie de l'Agriculture de France 64, 1117-1126.

Huglin, P. and Schneider, C. (1998) Biologie et écologie de la vigne (Lavoisier: Paris).
Jackson, D.I. and Lombard, P.B. (1993) Environmental and management practices affecting grape composition and wine quality: a review. American Journal of Enology and Viticulture 4, 409-430.

Jackson, R.S. (2000) Wine science. Principles, practice, perception, 2nd edn (Academic Press: San Diego, CA).

Jones, G. and Davis, R. (2000) Climate influences on grapevine phenology, grape composition, and wine production and quality for Bordeaux, France. American Journal of Enology and Viticulture 51, 249-261.

Jones, G.V., Duff, A.D., Hall, A. and Myers, J.W. (2010) Spatial analysis of climate in winegrape growing regions in the western United States. American Journal of Enology and Viticulture 61, 313-326.

Jones, G., Moriondo, M., Bois, B., Hall, A. and Duff, A. (2009) Analysis of the spatial climate structure in viticulture regions worldwide. Le Bulletin de l'Organisation Internationale de la Vigne et du Vin 82, 507-518.

Jones, G.V., White, M.A., Cooper, O.R. and Storchmann, K. (2005) Climate change and global wine quality. Climatic Change 73, 319-343.

Kliewer, W.M. (1973) Berry composition of Vitis vinifera cultivars as influenced by photo- and nycto-temperatures during maturation. Journal of the American Society for Horticultural Science 98, 153-159.

Kliewer, W.M. and Torres, R.E. (1972) Effect of controlled day and night temperatures on coloration of grapes. American Journal of Enology and Viticulture 23, 71-77.

Mullins, M.G., Bouquet, A. and Williams, L.E. (1992) Biology of the grapevine (Cambridge University Press: Cambridge, New York).

Penman, H.L. (1948) Natural evaporation from open water, bare soil, and grass. Proceedings of the Royal Society of London Series A 193, 120-146. Ramos, M.C., Jones, G.V. and Martinez-Casasnovas, J.A. (2008) Structure and trends in climate parameters affecting winegrape production in northeast Spain. Climate Research 38, 1-15.

Servicio Agrícola y Ganadero (SAG) (2010) Ley 18455 y reglamento. Electronic resource (Ministerio de Agricultura de Chile, Santiago).

Soar, C.J., Sadras, V.O. and Petrie, P.R. (2008) Climate drivers of red wine quality in four contrasting Australian wine regions. Australian Journal of Grape and Wine Research 14, 78-90.

Tonietto, J. (1999) Les macroclimats viticoles mondiaux et l'influence du mésoclimat sur la typicité de la Syrah et du Muscat de Hambourg dans le Sud de la France: méthodologie de caractérisation. PhD Thesis, Ecole Nationale Supérieure Agronomique de Montpellier, Montpellier, France, $233 \mathrm{pp}$.

Tonietto, J. and Carbonneau, A. (2004) A multicriteria climatic classification system for grapegrowing regions worldwide. Agricultural and Forest Meteorology 124, 81-97.

Vaudour, E. (2003) Les terroirs viticoles (Dunod: Paris).

Ward, J.H. (1963) Hierarchical grouping to optimize an objective function. Journal of the American Statistical Association 58, 236-244.

Wilks, D.S. (2006) Statistical methods in the atmospheric sciences, 2nd edn International Geophysics Series, Vol. 59 (Academic Press: San Diego).

Willocquet, L. and Clerjeau, M. (1998) An analysis of the effects of environmental factors on conidial dispersal of Uncinula Necator (grape powdery mildew) in vineyards. Plant Pathology 47, 227-233.

Wines of Chile (2011) The wine regions of Chlie. http://www.winesof chile.org [accessed 19/03/11].

Winkler, A.J., Cook, J.A., Kliewer, W.M. and Lider, L.A. (1974) General viticulture (University of California Press: Berkeley, Los Angeles, London).

\section{Manuscript received: 4 June 2011}

Revised manuscript received: 29 July 2011

Accepted: 7 August 2011

\section{Supporting information}

Additional Supporting Information may be found in the online version of this article: http://onlinelibrary.wiley.com/doi/ $10.1111 /$ j.1755-0238.2011.00165.x/abstract

Figure S1. Day length (hours) between $30^{\circ} \mathrm{S}$ and $50^{\circ} \mathrm{S}$ from October to March. Right panel displays the HI adjustment factor (d) for different latitudes (dotted line shows where $d=1.0$, which occurs at $233.3^{\circ} \mathrm{S}$ ).

Please note: Wiley-Blackwell are not responsible for the content or functionality of any supporting materials supplied by the authors. Any queries (other than missing material) should be directed to the corresponding author for the article. 